\title{
A Design Criteria of Ventilation Holes to Reduce a Vapor Condensation on the Balcony Walls in Apartment Housings
}

\author{
Jong-Sung Lee ${ }^{1}$, Jong-Yeob Kim ${ }^{2}$, Ha-Jin Hwang ${ }^{3}$ and Sung-Bok Lee ${ }^{4}$ \\ (Received September 6, 2011 / Revised October 14, 2011 / Accepted October 27, 2011)
}

\begin{abstract}
LH has installed sashes to the balcony to save energy and increase residential space. Then, it is very difficult to protect a condensation of vapor on the walls in the winter time, because the space is closed and the wall surface temperature becomes very low in a balcony. We have tried to get the optimal thermal design methods to reduce the condensation on the walls. The one of the chosen method is to make holes on the walls, and then the condensation shall be reduce because the dew point temperature will be lower due to the effect of dehumidify. In this case, it is just necessary to find as like that how many holes should be perforated through the wall, what's their size, and where is their positions. In this study, a computational fluid dynamics was applied to analyze the temperature, the pressure and the velocity distribution for an incompressible flow in the balcony spaces. And field tests were also carried out to get the data to compare to the simulation results. Finally the design criteria of the ventilation holes in the balconies was suggested by analysis of the computer simulation models.
\end{abstract}

Keywords: Apartment housings, Balcony, Ventilation hole, Vapor condensation, CFD

\section{Introduction}

The Rental Housing Act was amended to be able to install a sash to apartment balconies. Since the Act has took effect on, LH has installed sashes to the balcony to save energy and increase residential space. Then, it is very difficult to protect the condensation of vapors on the walls in there because the space is closed and the wall surface temperature becomes very low. If the condensation occurs on the wall, it is clear that residents are displeased with the situation.

So, we have tried to get the optimal design criteria to reduce the condensation on the wall, and the chosen method is to make holes on it. In this case, it is natural that the condensation shall be reduce because the dew point temperature is lower than the space without holes. In this case, it is just necessary to find as like that how many holes should be perforated into the wall, what is their size, and where is their positions.

In this study, a computer simulation for three dimensional incompressible flows shall be considered to analyze temperature, pressure and velocity distribution in balconies. Also the field tests shall be carried out to get the date comparing to the simulation results. Finally, the design criteria for the holes shall be suggested by a computer simulation after demonstration of the simulation modeling.

\section{Field test}

\subsection{Purpose}

The interested houses for a field test are two houses which have same area of $46 \mathrm{~m}^{2}$. One is located in Chun-cheon and the other is in Dong-hae. Figure 1 shows their planes. The measuring values are temperature of air and wall surface, fluid velocity in the balconies, wind velocity, and humidity in the balconies, rooms, outdoor air. The purposes of a field test are to get the boundary condition data to be applied a CFD simulation program, and to get the data comparing with a simulation data.

\subsection{Measurement system}

Figure 2 shows the schematic diagram of the measurement system which can measure and record temperature, fluid flow,

1) Research Fellow, Land \& Housing Institute (Main author: jslee1@lh.or.kr)

2) Senior Research Fellow, Land \& Housing Institute (Corresponding author: jykimgreen@lh.or.kr)

3) Research Fellow, Land \& Housing Institute

4) Senior Research Fellow, Land \& Housing Institute 
and humidity. Table 1 shows a specifications of the measuring instruments. The 60 thermocouples were set up to measure the temperature of living room and walls, and 72 thermocouples were set up to measure the fluid temperature in balcony: the 3 zones with 4 points in the direction of width and 6 points in it of heigh. Also 3 hygrometers were set up to room, balcony and the outdoor air.

\section{Computer Simulation of Heat and Fluid Flow in the Balcony}

In this chapter, the fluid flow and temperature distributions in balcony shall be calculated by computer simulation. It is reasonable that the fluid is inviscid, incompressible, turbulent, and natural convection. The SC/Tetra; a code which has been applied generally to engineering field for an analysis of a fluid flow and heat transfer, was used to calculate the fluid velocity and temperature. It has been well known as good converging code for a turbulent flow and natural convection models.

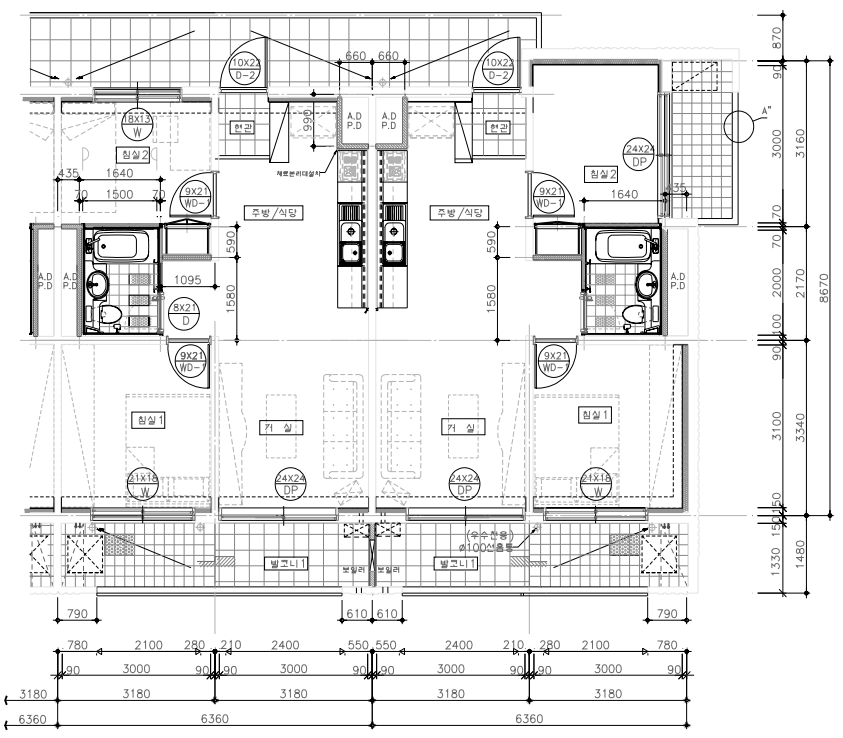

Fig. 1. Plane view of the field test house

\subsection{Governing Equations}

As previously stated, the fluid in balcony is turbulent because the Rayleigh number is about $4.67 \times 10^{9}$; this value was measured by the field test. It also is incompressible because density is constant due to a time variation. And it is natural convection because the velocity is very low, about $3 \sim 20 \mathrm{~cm} / \mathrm{s}$. So, the governing equations of the fluid in the balcony are as follows.

1) The equation of continuity

$$
\frac{\partial u_{i}}{\partial x_{i}}=0
$$

2) The equation of motion

$$
\frac{\partial u_{i}}{\partial t}+\frac{\partial u_{j} \rho u_{i}}{\partial x_{j}}=-\frac{\partial p}{\partial x_{i}}+\frac{\partial}{\partial x_{j}} \mu \frac{\partial u_{i}}{\partial x_{j}}-g_{i} \rho \beta\left(T-T_{0}\right)
$$

3) The equation of energy

$$
\frac{\partial \rho C_{p} T}{\partial t}+\frac{\partial u_{i} \rho C_{p} T}{\partial x_{j}}=\frac{\partial}{\partial x_{j}} K \frac{\partial T}{\partial x_{j}}+q
$$

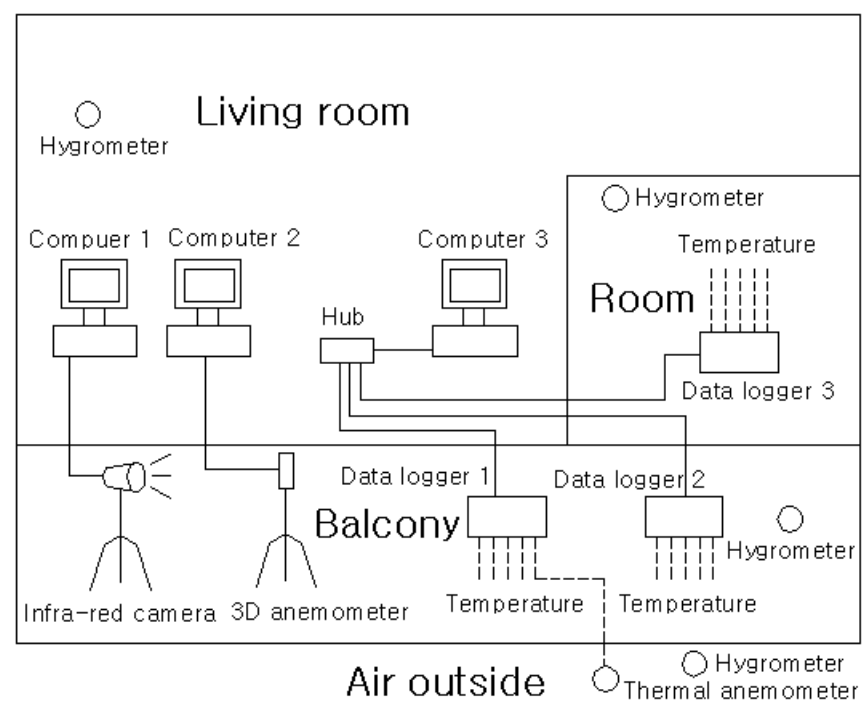

\begin{tabular}{|c|c|c|c|}
\hline \multicolumn{2}{|r|}{ Measurement items } & Instruments & a note \\
\hline \multirow{2}{*}{ Temperature } & Air (balcony, room, outside) and surface temperature & T-type thermocouple (C-C sensor) & Error range : $\pm 0.5^{\circ} \mathrm{C}$ \\
\hline & Surface & Infrared camera (IRE S-400) & USA IRE \\
\hline \multirow{2}{*}{ Aerofoil } & Flow direction and velocity & 3 dimensional supersonic anemometer (WA-590) & Japan KAIJO \\
\hline & Wind velocity & Thermal anemometer (TSI 8465) & USA TSI \\
\hline $\begin{array}{l}\text { write/ } \\
\text { storage }\end{array}$ & Data storage & Notebook computer & Korea \\
\hline
\end{tabular}

Fig. 2. Schematic diagram of the measurement system

Table 1. Specification of the measuring instruments 
4) The equations of turbulent energy and dissipation rate $(\mathrm{k}-\varepsilon$ equation)

$$
\begin{aligned}
& \frac{\partial \rho k}{\partial t}+\frac{\partial}{\partial x_{i}}=\frac{\partial}{\partial x_{i}}\left(\frac{\mu_{t} \partial k}{\sigma_{k} \partial x_{i}}\right)+G_{\delta}+G_{\tau}+\rho_{\epsilon} \\
& \frac{\partial \rho_{\epsilon}}{\partial t}+\frac{\partial u_{i} \rho \epsilon}{\partial x_{i}}=\frac{\partial}{\partial x_{i}}\left(\frac{\mu_{i} \partial \epsilon}{\sigma_{\epsilon} \partial x_{i}}\right)+C_{1} \frac{\epsilon}{k}\left(G_{s}+G_{\tau}\right)\left(1+C_{3} R_{f}\right)-C_{2} \frac{\rho \epsilon^{2}}{k}
\end{aligned}
$$

\subsection{Modeling}

\subsubsection{Geometry}

Figure 3 shows a geometry for a computer simulation. This geometry is same with the field test houses except cutting the symmetry regions to reduce a computer calculation memory.

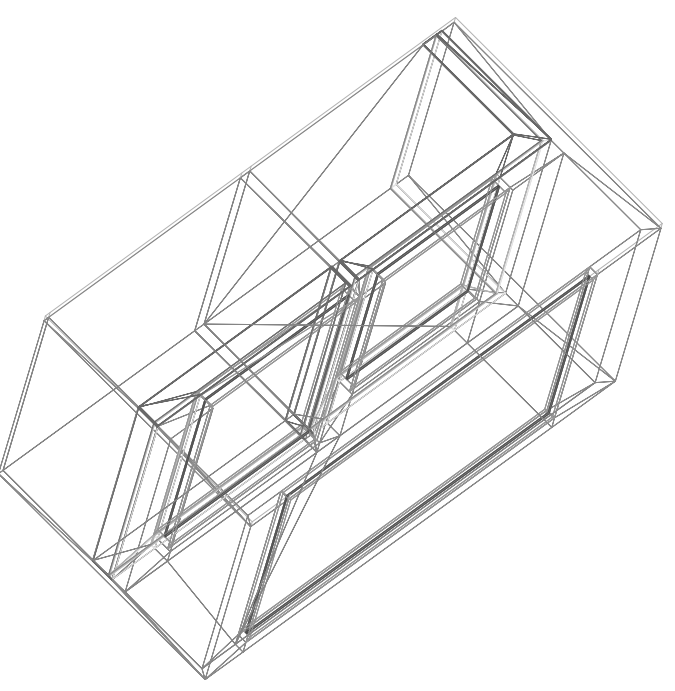

Fig. 3. Geometry for a computer simulation

\subsubsection{Properties and Bboundary Conditions}

\section{(1) Properties}

Many properties are required to calculate the fluid flow and temperature characteristics of indoor air, i.e., density, specific heat, conductivity, viscosity, and expansion coefficient for a reference temperature. Table 2 shows the properties of materials.

Table 2. Properties of materials

\begin{tabular}{c|c|c|c|c|c}
\hline Items & $\begin{array}{c}\text { Conductivity } \\
(\mathrm{W} / \mathrm{mK})\end{array}$ & $\begin{array}{c}\text { Specific heat } \\
(\mathrm{J} / \mathrm{kgK})\end{array}$ & $\begin{array}{c}\text { Density } \\
\left(\mathrm{kg} / \mathrm{m}^{3}\right)\end{array}$ & $\begin{array}{c}\text { Viscosity } \\
(\mathrm{kg} / \mathrm{ms})\end{array}$ & $\begin{array}{c}\text { Expansion } \\
\text { coefficient } \\
\left(\mathrm{K}^{-1}\right)\end{array}$ \\
\hline Concrete & 1.6 & 880 & 2,100 & - & - \\
\hline Insulation & 0.037 & 1,210 & 50 & - & - \\
\hline Dew protector & 0.065 & 840 & 300 & - & - \\
\hline Gypsum board & 0.18 & 1,134 & 910 & - & - \\
\hline Glass(5-6-5) & 0.147 & 745 & 1,500 & - & - \\
\hline Flame & 0.175 & 1,930 & 1,250 & - & - \\
\hline Air & 0.0256 & 1,007 & 1.177 & $1.83 \mathrm{e}-05$ & $1 / \mathrm{T}$ \\
\hline
\end{tabular}

\section{(2) Boundary Conditions}

Table 3 shows the boundary conditions to be applied to the simulation model.

Table 3 . boundary conditions

\begin{tabular}{c|l}
\hline Items & \multicolumn{1}{|c}{ Boundary conditions } \\
\hline Inlet air & air temperature, Velocity, k- $\varepsilon$ values \\
\hline outlet air & Static pressure = Constant \\
\hline Cutting surface & Adiabatic, Free-slip \\
\hline Overlapped walls & Free-slip, No thermal resistance \\
\hline Surface of walls & Non-slip, Log law condition \\
\hline Floor & floor temperature, overall heat transfer coefficient \\
\hline
\end{tabular}

\subsubsection{Comparison with the Simulation Results and the Measuring Data}

\section{(1) Air Temperature in Balcony}

The period of comparison was about a.m. 4:00 when the outdoor air was low enough and became steady state. Then the outside air temperature was about $-5^{\circ} \mathrm{C}$, wind velocity was $0.7 \mathrm{~m} / \mathrm{s}$, and floor surface temperature was about $30^{\circ} \mathrm{C}$. Figure 4 and Figure 5 show the measuring data and simulation data each

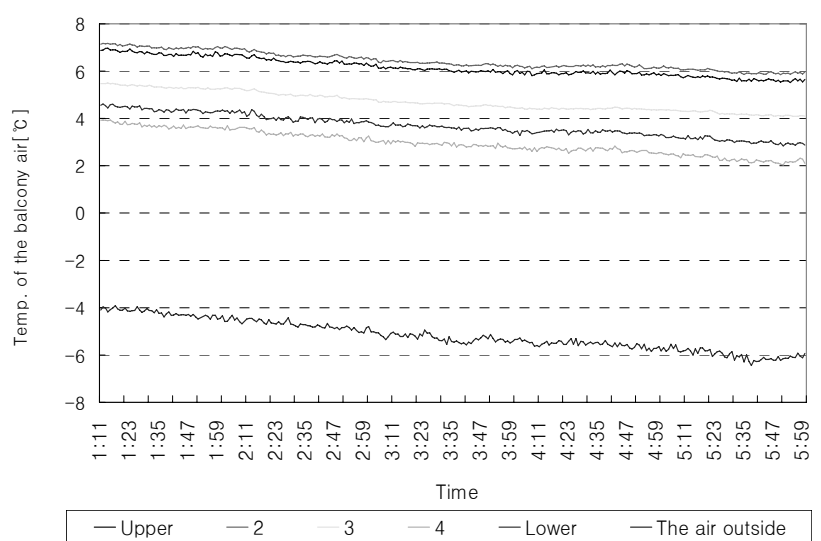

Fig. 4. Air temperature distribution in balcony from lower part to upper part at the middle region (Field test)

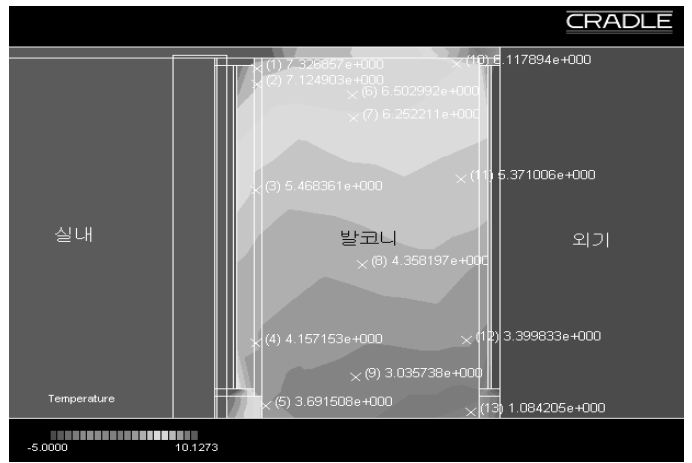

Fig. 5. Air temperature distribution in balcony by a computer simulation 
other. The measuring data are the values from lower part to upper part at the middle point with the width direction of balcony. The temperature distribution from the lower to upper parts is $3{ }^{\circ} \mathrm{C} \sim 6^{\circ} \mathrm{C}$, and it is almost equal to the simulation data of the figure 5 .

\section{(2) Surface Temperature}

Figure 6 shows the simulation result for the surface temperature of wall, glass, and window frame. Figure 7 shows the surface temperature difference with the simulation results and measuring data. It looks like that two results are about the same.

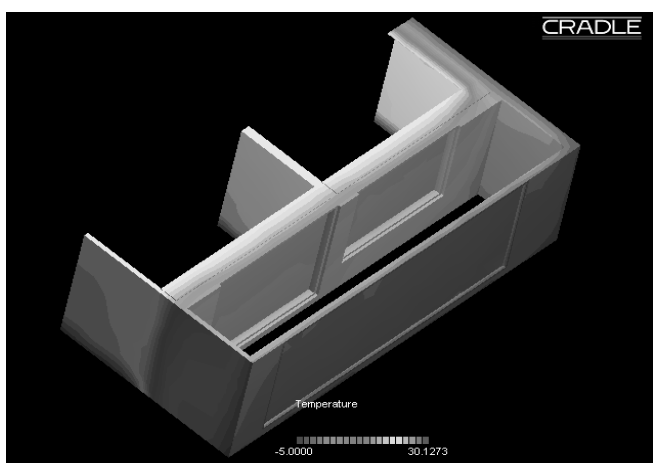

Fig. 6. Temperature distribution of the surface by a computer simulation

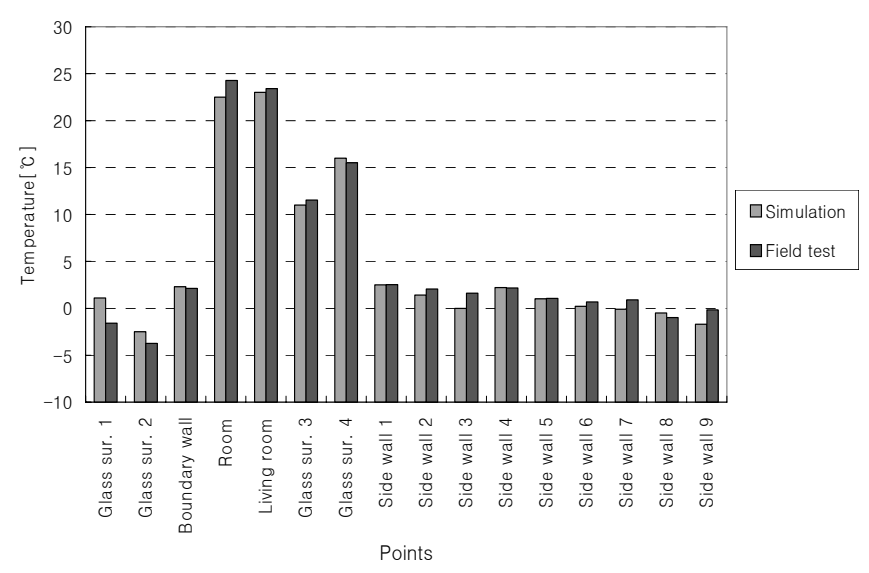

Fig. 7. Comparison with simulation result and measuring data

\section{(3) Fluid Flow Distribution in the Balcony}

Figure 8 is the results when the outdoor air temperature was $2^{\circ} \mathrm{C}$, the room temperature was about $26^{\circ} \mathrm{C}$. Figure 8 (a) shows the measured fluid velocity vector in balcony, and the (b) and the (c) show the flow direction and velocity by a computer simulation. The (a) shows that the velocity is $3 \sim 13 \mathrm{~cm} / \mathrm{s}$, and the flow direction is equal to the sum of the direction of gravity and heat transfer. As shown to the (b) and the (c), the velocity is about $2 \sim 14 \mathrm{~cm} / \mathrm{s}$, and the fluid direction is the about same with (a).

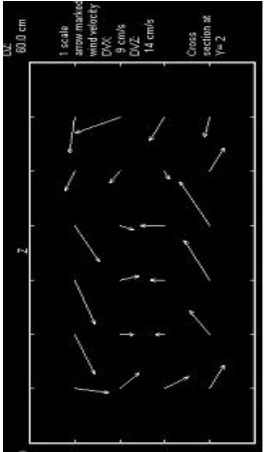

(a) Measurement

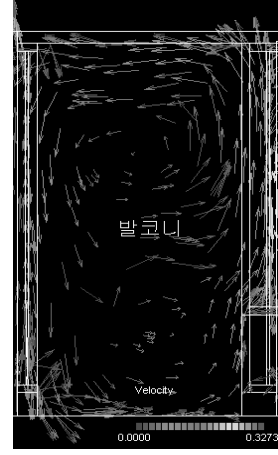

(b) Simulation(vector)

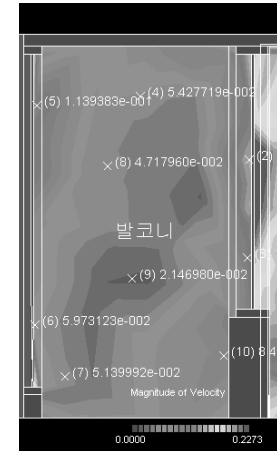

(c) Simulation(velocity)
Fig. 8. Comparison of the fluid flow with simulation and measured data

\section{Ventilation Plan to Reduce a Vapor Condensation on the Balcony Walls}

\section{$4.184 \mathrm{~m}^{2}$ Apartment Housing}

\subsubsection{Closed Balcony Space (No Ventilation Holes)}

Figure 9 shows the air temperature distribution by simulation to the middle height of the $84 \mathrm{~m}^{2}$ apartment housings' balcony. It is almost constant to the internal zone of balcony, but it is very irregular along the perimeter zone. Also the temperature is high along the inside perimeter zone, and it is low along the outside. That is because the heat transfer resistance is high near the wall surface due to the thick boundary layer. Figure 10 shows the velocity at the same position. It is clear that the air is stagnated at corners and wall surface, so the boundary layer is thick along the

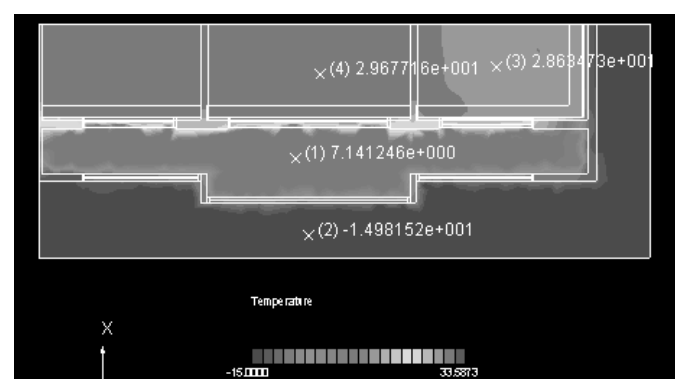

Fig. 9. Air temperature distribution for $84 \mathrm{~m}^{2}$

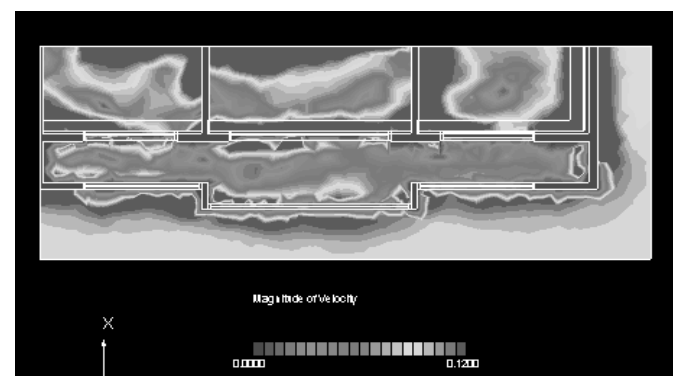

Fig. 10. Velocity distribution for the $84 \mathrm{~m}^{2}$ 
regions. Figure 11 shows the surface temperature. Figure 12 shows the possibility of a vapor condensation on the wall. The condensation may be happened to the most part of a wall.

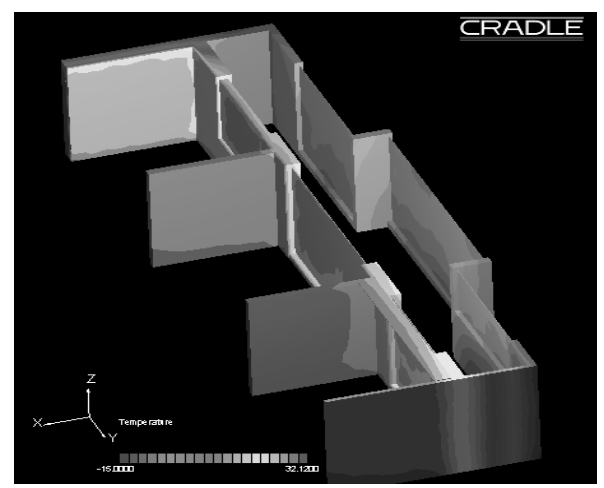

Fig. 11. Temperature distribution on the wall surface for the $84 \mathrm{~m}^{2}$

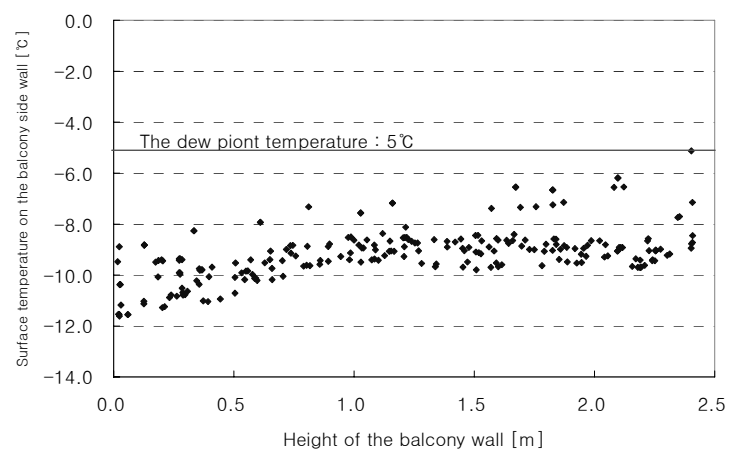

Fig. 12. Possibility of the vapor condensation on the balcony wall of the $84 \mathrm{~m}^{2}$

\subsubsection{Open Space (Perforated Holes for Ventilation)}

\section{(a) Model}

Fig. 13 shows the drawing of which 4 holes are perforated into the concrete wall. Then it is clear that natural convection will be more active than the closed space. Figure 14 shows the geometry made by SC/Tetra Code.

\section{(b) Results}

Figure 15 shows the vapor condensation area ratio on the wall. It is $79.1 \%$ if the diameter of holes is $0 \mathrm{~mm}$ : it is the same with a closed space. It is about $79 \%$ when the 4 holes with $30 \mathrm{~mm}$ diameter are perforated through the wall. If 4 holes with $70 \mathrm{~mm}$ diameter will be perforated, the possibility may be about $3.5 \%$. In the case of two holes with $100 \mathrm{~mm}$ diameter, which one is up of the left and the other is down of the right, then the possibility is $0 \%$. But if the both holes are to the same height, for example, upper or middle or lower, it is not good design method to protect the vapor condensation. Figure 16 shows an average air temperature in the balcony. The area of holes is more larger and larger, it is getting lower and lower. (the sign of hole designs type refer to the conclusion)

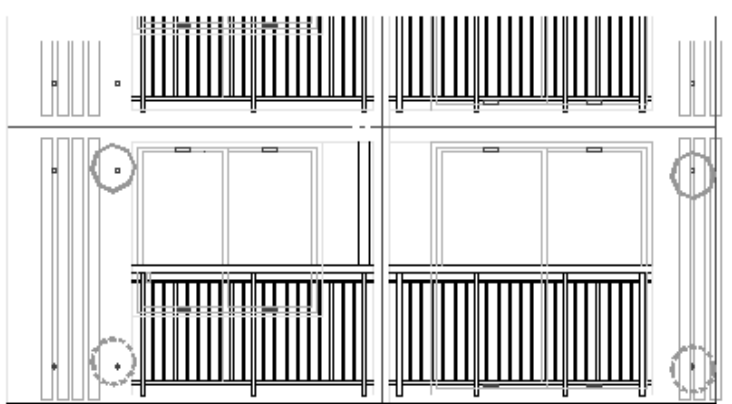

Fig. 13. Perforated holes for natural convection

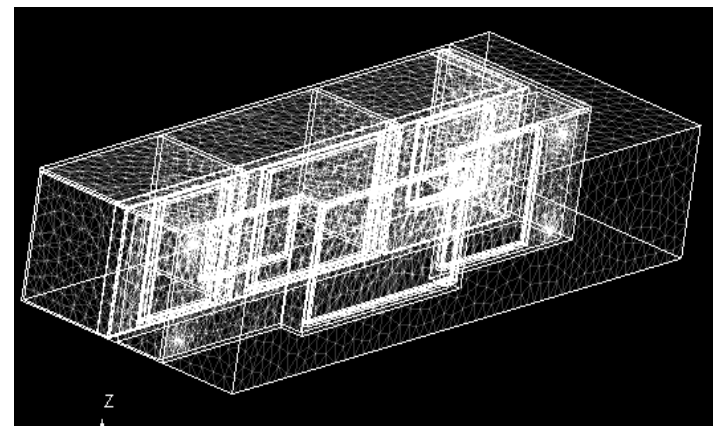

Fig. 14. Geometry made by the SC/Tetra Code

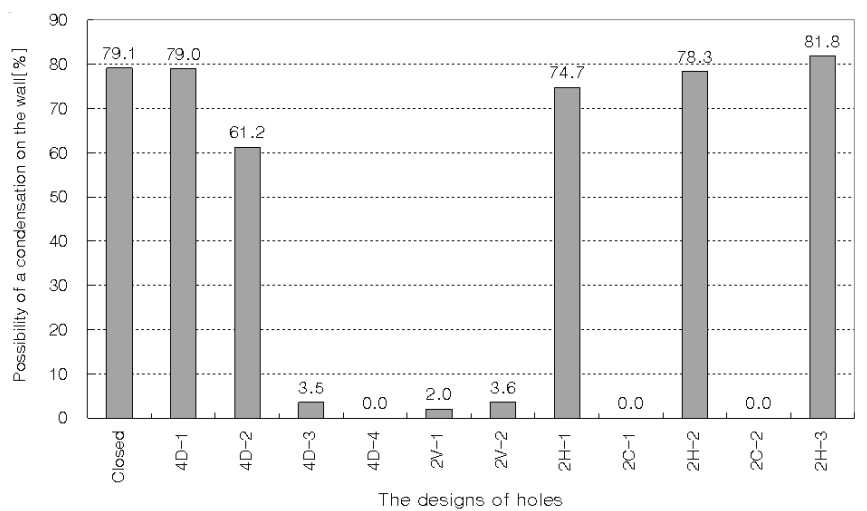

Fig. 15. Vapor condensation area ratio on the balcony wall for the $84 \mathrm{~m}^{2}$

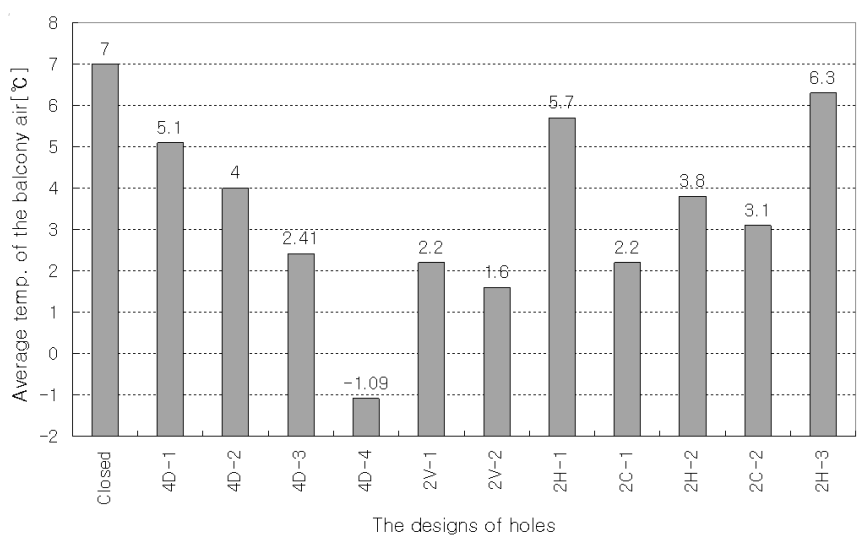

Fig. 16. Air temperature in balcony per the hole designs for the $84 \mathrm{~m}^{2}$ 


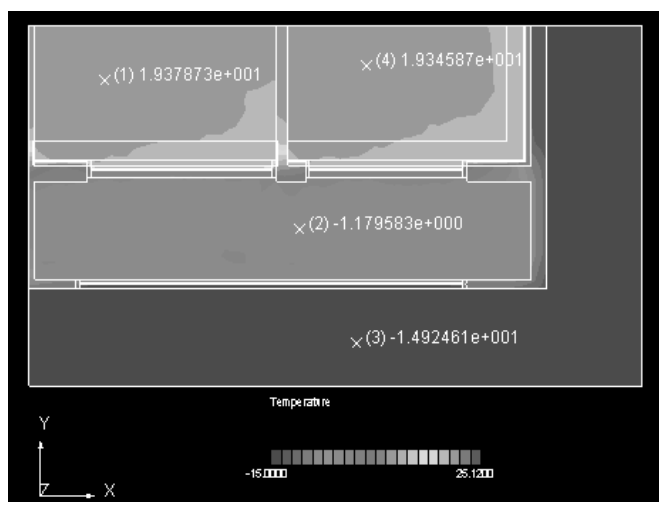

Fig. 17. Air temperature distribution for the $46 \mathrm{~m}^{2}$

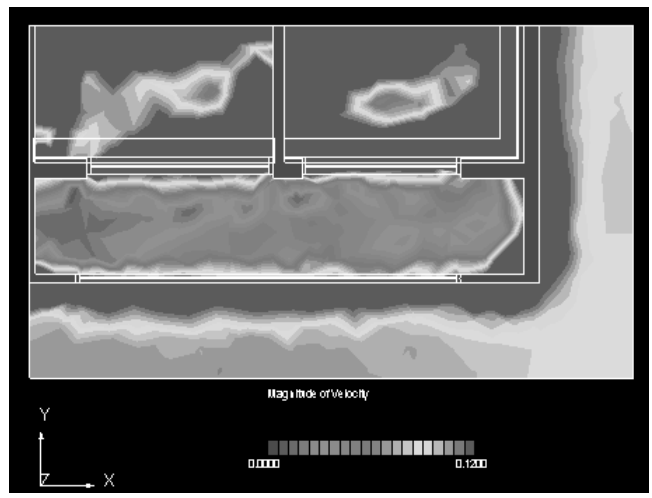

Fig. 18. Velocity distribution for the $46 \mathrm{~m}^{2}$

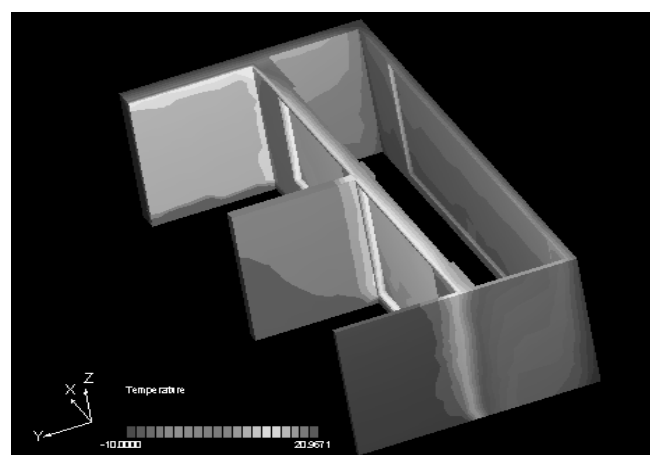

Fig. 19. Surface temperature for the $46 \mathrm{~m}^{2}$

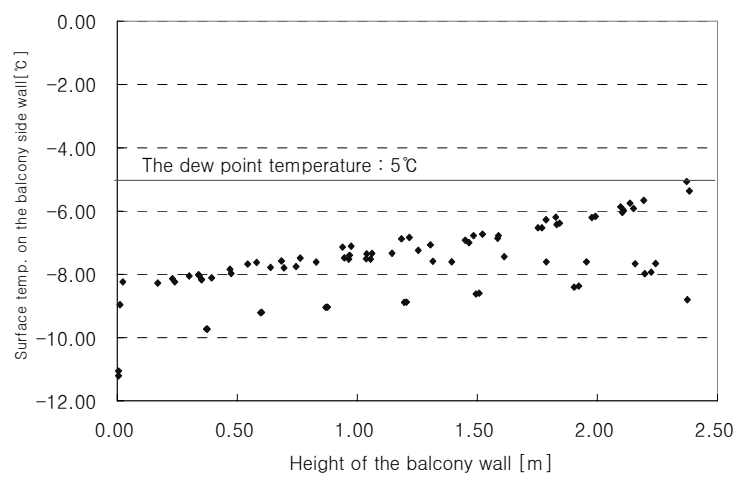

Fig. 20. Possibility of the condensation on the balcony wall for the $46 \mathrm{~m}^{2}$

\section{$4.246 \mathrm{~m}^{2}$ Apartment Housing}

\subsubsection{Closed Balcony Space (No Ventilation Holes)}

Figure 17 shows the air temperature distribution by simulation for the $46 \mathrm{~m}^{2}$ apartment housing. The balcony air temperature is almost constant to the internal zone and the perimeter zone. This result is different from that of the $84 \mathrm{~m}^{2}$ apartment housing. Moreover, the room temperature of this plane is more lower than that of the $84 \mathrm{~m}^{2}$. It is guessed that the flow and temperature characteristics are dissimilar to each other because the shape of the balcony planes are different from each other.

Figure 18 shows the velocity distribution in the balcony plane. As shown in this figure, the velocity is very fast at the corners and nearby the surface. So the convective heat transfer coefficient is very high at the region, and then heat is get out very well from the room to outdoor air. So the air temperature in the balcony and rooms of $46 \mathrm{~m}^{2}$ is more lower than that of the $84 \mathrm{~m}^{2}$.

Figure 19 shows the surface temperature, and figure 20 shows the possibility of a vapor condensation on the walls. A vapor condensation will be happened almost balcony wall surface as same as the $84 \mathrm{~m}^{2}$.

\section{2) Open Space (Perforated Holes for Ventilation)}

The holes for ventilation are also perforated through the concrete wall in the same method with $84 \mathrm{~m}^{2}$ apartment housing. Then, figure 21 shows the vapor condensation area ratio on the balcony wall. It is about $77 \%$ when the balcony space is closed, i.e. the diameter of holes is $0 \mathrm{~mm}$. And it is about $47 \%$ for four holes with diameter $30 \mathrm{~mm}$, and it is $0 \%$ for four holes with diameter $50 \mathrm{~mm}$. If there are two holes with $70 \mathrm{~mm}$ diameter which one is down of the left and the other is up of the right, it is also $0 \%$.

Figure 22 shows the average air temperature in the balcony. It is about $-1{ }^{\circ} \mathrm{C}$ in case of closed space, however, it is more higher if the holes are perforated. It is because the temperature is calculated for the only middle section of balcony space. If the average temperature would be calculated for all of the region in balcony it will be more lower than that of the closed space.

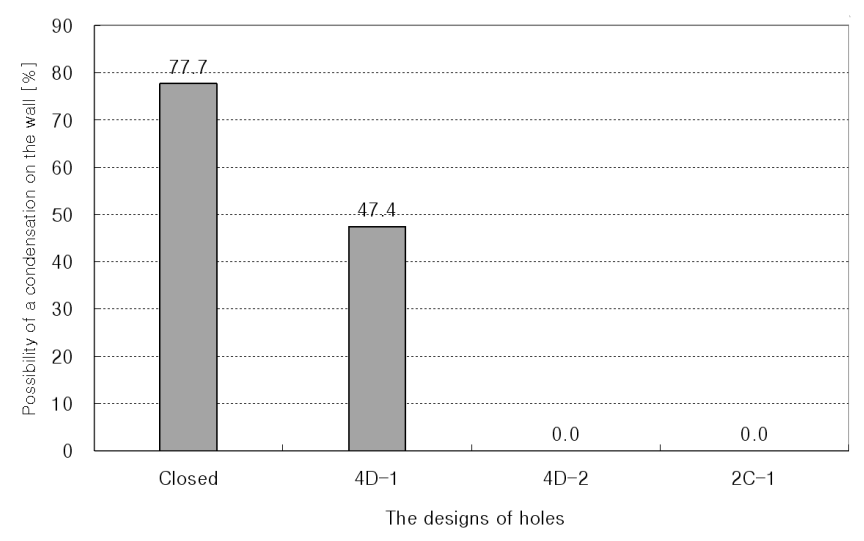

Fig. 21. Vapor condensation area ratio on the balcony wall for the $46 \mathrm{~m}^{2}$ 


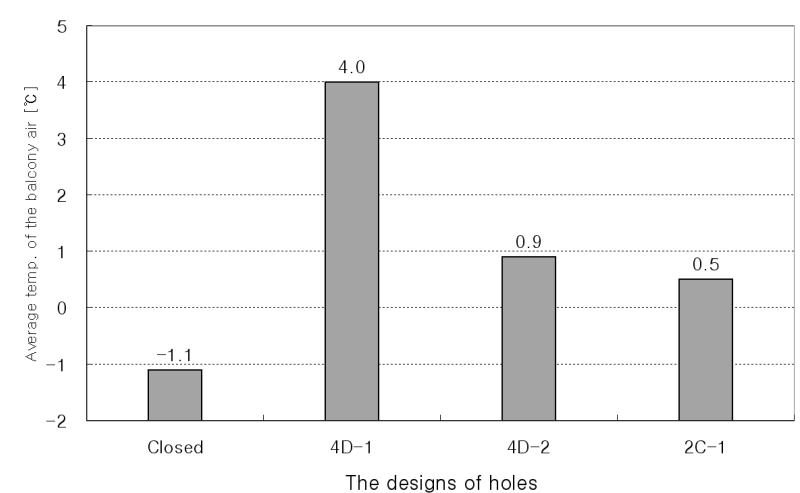

Fig. 22. Air temperature in balcony per the hole designs for the $46 \mathrm{~m}^{2}$

\section{Conclusion}

In this study, a field test and a computer simulation were performed to find the optimal design criteria of ventilation holes reducing the vapor condensation on the balconies wall. The results of a simulation modeling using the $\mathrm{SC} /$ Tetra Code was about similar with the results of the field test data. So, the optimal design criteria was proposed by the computer simulation analysis. Table 4 shows the proposed design criteria.

Table 4. Design criteria of ventilation holes to reduce the vapor condensation on the balcony wall

\begin{tabular}{|c|c|c|c|c|c|c|}
\hline \multicolumn{2}{|c|}{ Designs } & \multirow{2}{*}{$\begin{array}{c}\frac{D^{\text {Diameter }}}{(\mathrm{m})} \\
0\end{array}$} & \multirow{2}{*}{\begin{tabular}{|c|}
$\begin{array}{c}\text { Area ratio of } \\
\text { condensation } \\
\text { (\%) }\end{array}$ \\
79 \\
\end{tabular}} & \multirow{2}{*}{\begin{tabular}{|c}
$\begin{array}{c}\text { Air temp. in } \\
\text { balcony } \\
\left({ }^{\circ} \mathrm{C}\right)\end{array}$ \\
7
\end{tabular}} & \multirow{2}{*}{$\begin{array}{c}\text { Choice } \\
\times\end{array}$} & \multirow{2}{*}{$\begin{array}{c}\begin{array}{c}\text { Note } \\
\text { (The position of } \\
\text { holes) }\end{array} \\
\begin{array}{c}\text { Closed space } \\
\text { (present) }\end{array} \\
\end{array}$} \\
\hline \multirow{12}{*}{$84 \mathrm{~m}^{2}$} & Type 1 & & & & & \\
\hline & 4D-1 & 0.03 & 79 & 5.1 & $x$ & $\begin{array}{c}4 \text { holes } \\
\text { (R/L: up and down) }\end{array}$ \\
\hline & $4 \mathrm{D}-2$ & 0.05 & 61 & 4 & $x$ & $\begin{array}{c}4 \text { holes } \\
\text { (R/L: up and down) }\end{array}$ \\
\hline & 4D-3 & 0.07 & 4 & 2.4 & $\triangle$ & $\begin{array}{c}4 \text { holes } \\
\text { (R/L: up and down) }\end{array}$ \\
\hline & 4D-4 & 0.1 & 0 & -1.1 & $\bigcirc$ & $\begin{array}{c}4 \text { holes } \\
\text { (R/L: up and down) }\end{array}$ \\
\hline & $2 \mathrm{~V}-1$ & 0.1 & 2 & 2.2 & $\triangle$ & $\begin{array}{c}2 \text { holes } \\
\text { (R: up and down) }\end{array}$ \\
\hline & $2 \mathrm{~V}-2$ & 0.1 & 4 & 1.6 & $\triangle$ & $\begin{array}{c}2 \text { holes } \\
\text { (L: up and down) }\end{array}$ \\
\hline & $2 \mathrm{H}-1$ & 0.1 & 75 & 5.7 & $x$ & $\begin{array}{c}2 \text { holes } \\
\text { (R: up, L: up) }\end{array}$ \\
\hline & $2 \mathrm{H}-2$ & 0.1 & 79 & 3.8 & $\times$ & $\begin{array}{c}2 \text { holes (R: middle, } \\
\text { L: middle) }\end{array}$ \\
\hline & $2 \mathrm{H}-3$ & 0.1 & 82 & 6.3 & $x$ & $\begin{array}{c}2 \text { holes } \\
\text { (R: down, L: down) }\end{array}$ \\
\hline & $2 \mathrm{C}-1$ & 0.1 & 0 & 2.5 & $\bigcirc$ & $\begin{array}{l}2 \text { holes } \\
\text { (R: down L: up) }\end{array}$ \\
\hline & $2 \mathrm{C}-2$ & 0.1 & 0 & 3.1 & () & $\begin{array}{c}2 \text { holes } \\
\text { (R: up L: down) }\end{array}$ \\
\hline \multirow{4}{*}{$46 \mathrm{~m}^{2}$} & Type 1 & $0 \mathrm{~mm}$ & 78 & -1.1 & $x$ & $\begin{array}{c}\text { Closed space } \\
\text { (present) }\end{array}$ \\
\hline & 4D-1 & 0.03 & 47 & 4 & $x$ & $\begin{array}{c}4 \text { holes } \\
\text { (R/L: up and down) }\end{array}$ \\
\hline & $4 \mathrm{D}-2$ & 0.05 & 0 & 0.9 & $\bigcirc$ & $\begin{array}{c}4 \text { holes } \\
\text { (R/L: up and down) }\end{array}$ \\
\hline & $2 \mathrm{C}-1$ & 0.07 & 0 & 0.5 & (0) & $\begin{array}{c}2 \text { holes } \\
\text { (R: up L: down) }\end{array}$ \\
\hline
\end{tabular}

Note: 1. R : Right, L : Left, R/L : Right and left

2. Right is side wall, and Left is symmetry wall to meet next door house
As these results, it is the optimal design criteria for the $84 \mathrm{~m}^{2}$ that two holes with $100 \mathrm{~mm}$ diameter are perforated through the balcony outside wall, where one is a lower part of the symmetry wall and the other is an upper part of the side wall. The 2 holes with $70 \mathrm{~mm}$ diameter is optimal for the $46 \mathrm{~m}^{2}$, as same as position with $84 \mathrm{~m}^{2}$.

\section{Reference}

1. Brice, C., H. Luther and J. Wilkes (1969), Applied Numerical Methods, John Wiley \& Sons, Inc. pp. 429 464.

2. Grimson, J. (1971), Advanced Fluid Dynamics and Heat Transfer, McGraw-Hill Book Company, pp. 119 128.

3. Hoffmann, K. A. (1989), Computational Fluid Dynamics for Engineers, Engineering Education System, pp. 50 77 .

4. Mills, A. F. and R. Irwin (1995), Heat and Mass Transfer, Inc., pp. $244 \sim 268$.

5. Jonh, J. and W. Haberman (1989), Fluid dynamic, Bo-Sung Inc., pp. $68 \sim 87$.

6. Software Cradle (1998), SCRYU/Tetra version 4 (Pre, Slover, Post, Training manual), Software Cradle Co., Ltd. 